\title{
Dynamic patterns of mononucleated myogenic cell populations in the developing rat hindlimb
}

\author{
ANTONIO S.J. LEE, NARA YOON, MAREE GOULD and MING ZHANG* \\ Anatomy Department, University of Otago, Dunedin, New Zealand
}

\begin{abstract}
Formation of an organ is governed by both the genetic programming of individual cells and dynamic interactions amongst different cell communities or the 'community effect'. Using the developing vertebrate limb muscle, we identified myogenic stem cell communities derived from migratory somitic cells. These cells express Pax3, a gene from the paired box (PAX) family of transcription factors and Pax7, a paralog of Pax3. Both Pax genes act upstream of myogenic regulatory factor (MRF) whose activation marks a specified myogenic lineage and subsequent differentiation. Quantitative analyses on the size of the individual cell populations revealed that Pax3 and MRF compartments remained constant. Further analysis showed that the size of the Pax7 cell population increased significantly. The pool of foetal MRF populations contained decreasing Pax3 and increasing Pax7 proportions. This increase is dynamic at the developmental stage. Upon abrupt disruption of the p38 regulatory pathway for myogenic differentiation, established kinetic patterns were significantly altered. Changes in the proportions of these myogenic subpopulations imply that a community effect involving dynamic interactions among differentiating cell communities may play a crucial role in correct maintenance and propagation of myogenic stem cells.
\end{abstract}

KEY WORDS: skeletal muscle, stem cell, Pax3, Pax7, community effect

\section{Introduction}

The 'community effect' is a fundamental developmental mechanism, which locks the differentiation programme 'on' permitting the cells to become fully differentiated. Formation of an organ is governed not only by the intrinsic genetic programming of each cell but also by the interactions amongst cell type communities within the developing organ (Buckingham, 2003, Cossu et al., 1995, Gurdon et al., 1993b). The community effect ensures that each cell receives signals from surrounding cells of its own kind (Aubin-Houzelstein et al., 1998, Cossu et al., 1995, Gurdon et al., 1993a, Gurdon et al., 1993b, Stuttem and Campos-Ortega, 1991, Yasuo and Lemaire, 1999).

Skeletal muscle formation (myogenesis) in the vertebrate limb is a unique process. All limb muscle fibres are generated from a group of several hundred cells undergoing long-range migration from limb adjacent somites (Christand Brand-Saberi, 2002, Kardon et al., 2002, Tajbakhsh, 2003). This small group of migrated cells expand (Nikovits et al., 2001) and sequentially give rise to three populations of myogenic precursor cells namely embryonic, foetal and adult myoblasts as development progresses (Stockdale, 1992). Embryonic and foetal myoblasts give rise to two generations of multinucleated muscle cells, primary and secondary myotubes respectively (Ontell, 1978, Ross et al., 1987), while adult myoblasts or satellite cells are the primary source of myonuclei for postnatal growth and muscle repair (Moss and Leblond, 1971, Zammit and Beauchamp, 2001). Embryonic, foetal and adult myoblasts form separate populations, expressing different transcription factors and different genes so that these cells will respond differently to similar environmental signals (Biressi et al., 2007).

A single mature muscle contains millions of myonuclei that are generated at different times by these three populations of myoblasts. The adult extensor digitorum longus (EDL) muscle in rats, for example, has about 3 million myonuclei (Zhang and McLennan, 1999), less than $1 \%$ of which originate from embryonic and foetal myoblasts (Zhang and McLennan, 1995) while the rest are added after birth by satellite cells. How a very limited number of the migrated myogenic progenitor cells expand for the massive

Abbreviations used in this paper: $\mathrm{E}$, embryonic; EDL, extensor digitorum longus muscle; HBSS, Hank's balanced salt solution; MAPK, mitogen-activated protein kinase; MRF, myogenic regulatory factor; MSC, myogenic stem cell; PBS, phosphate buffered saline; Pax, paired-box transcription factor; Phospho-p38, phosphorylated p38; TA, tibialis anterior muscle.

*Address correspondence to: Ming Zhang. Anatomy Department, University of Otago, P.O. Box 913, Dunedin 9054, New Zealand.Tel: +6434797378. Fax: +6434797254.
E-mail: ming.zhang @ otago.ac.nz - (DD http://orcid.org/0000-0002-5251-5810

Submitted: 25 May, 2017; Accepted: 11 December, 2017.

ISSN: Online 1696-3547, Print 0214-6282 
muscle mass remains a puzzle.

Relatively well-defined genetic hierarchy during skeletal muscle development allows us to examine and identify the developmental and differentiation states of myogenic progenitors and committed precursors (Buckingham et al., 2003, Tajbakhsh, 2005). In the developing limb buds before the start of myogenesis, the long range migratory myogenic progenitor cells from the somites (Bober et al., 1994, Kardon et al., 2002) are characterised by their expression of paired-box transcription factor, Pax3 (Bober et al., 1994, Williams and Ordahl, 1994). Whereas its paralogue, Pax7 is not expressed in these migrating cells but is transcribed later in a subset of cells (Relaix et al., 2004). The cells expressing Pax3 and/or Pax7 then undergo 'specification' during which, early muscle determination genes Myf5 and/or MyoD of myogenic regulatory factor (MRF) family are activated (Relaix et al., 2005, Weintraub et al., 1991).

In the mouse embryo at the onset of myogenesis, Myf5 is expressed the earliest at day 8 until day 14 post somite formation (Ott et al., 1991). Adult satellite cells originate from these progenitor cells (Biressi et al., 2007). Together with Mrf4, Myf5 directs embryonic multipotent cells into the myogenic lineage (Kassar-Duchossoy et al., 2004). At a later time point when MyoD is expressed, it directs the cells into the myogenic program in the absence of Myf5 and Mrf4 (Braun et al., 1992). Myogenin functions as a differentiation factor, forming functional muscle fibres (Hasty et al., 1993a). Although Myf4 is also a determination gene associated with maturation, it is expressed later in development than Myf5 (Kassar-Duchossoy et al., 2004). Myf5 and MyoD are expressed in dividing myoblasts committed to the myogenic lineage, however these proteins are induced only to allow withdrawal from the cell cycle and subsequent terminal differentiation (Lassar et al., 1994). Myf5 and MyoD in muscle act under the guidance of extracellular growth factors such as insulin and insulin-like growth factors. These factors promote skeletal muscle differentiation that is also involved in the activation of mitogen-activated protein kinases p38 (MAPK) (Moxham et al., 1996). Hence the p38 pathway plays an essential role in the in vitro differentiation of myoblasts (Zetser et al., 1999).

Fig. 1. Triple immunochemistry using antibodies against Pax3, Pax7 and MRF (a cocktail of antibodies against Myf-5, Myod and Myogenin). (A) Isolated cells from E18 TA and EDL muscles and (B) Cross sections of E16 EDL muscle showing the presence of $\mathrm{Pax}^{+}$(in green), $\mathrm{MRF}^{+}$ (in red), Pax3+(in blue) and the 7 subpopulation cell types in merged images. Bar, 20 um. (C) High magnification images of isolated cells show the intracellular protein expression patterns of Pax3, Pax7 and MRFs that define the 7 overlapping or mutually exclusive subpopulations (i.e. (1) sole-Pax3+, (5) sole $\mathrm{Pax}^{+}$, (7) sole-MRF+, (3) $\mathrm{Pax}^{+}$/ $\mathrm{Pax}^{+}$, (2) $\mathrm{Pax}^{+} / \mathrm{MRF}^{+}$, (6) $\mathrm{Pax}^{+} / \mathrm{MRF}^{+}$, and (4) $\mathrm{Pax}^{+} / \mathrm{Pax}^{+} /$ $\mathrm{MRF}^{+}$). Bar, $10 \mu \mathrm{m}$. (D) Schematic Venn diagram illustrating 3 communities $\left(\mathrm{Pax}^{+}, \mathrm{Pax}^{+}\right.$and $\left.\mathrm{MRF}^{+}\right)$and the 7 subpopulations. (E) Western blot analyses on muscle lysates from $E 15$ and $E 18$ embryos using anti-Pax3, -Pax7, -MyoD, -myf-5 and-myogenin antibodies.
As the level of MRF transcripts is accumulated (Weintraub etal., 1991), the levels of Pax3 and/or Pax7 are down regulated. Once the accumulated level of MRF transcripts reaches threshold, the cell is irreversibly committed to the myogenic lineage, becoming a myogenic precursor or a myoblast (Tajbakhsh, 2005). Further differentiation is driven by the later MRFs - myogenin and/or MRF4 (Hasty et al., 1993b), through which, fully differentiated, fusion-competent myoblasts emerge (Buckingham et al., 2003, Tajbakhsh, 2005). Therefore, cells at these different developmental and differentiation states must co-exist within the developing limb muscle. To our knowledge, no study has attempted to quantify the relative sizes of each cell populations and their potential changes during myogenesis.

The aim of this study was to use the developing vertebrate hindlimb muscle of the rat as a model to identify and classify populations of mononucleated myogenic progenitors and commit-
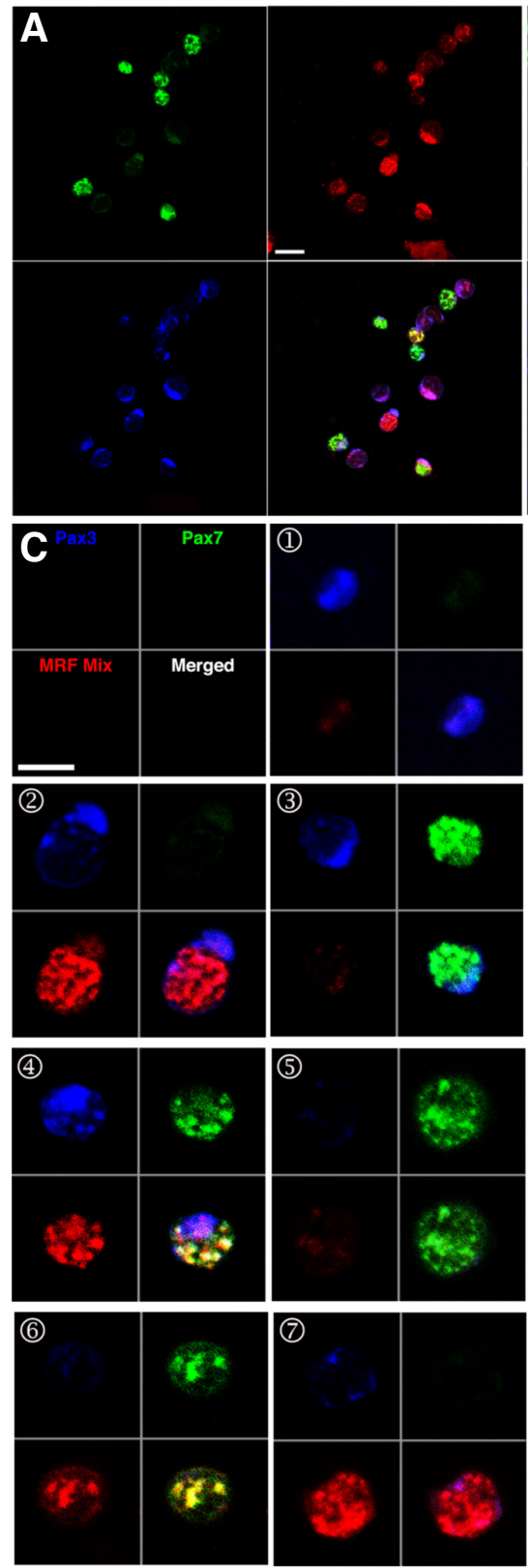

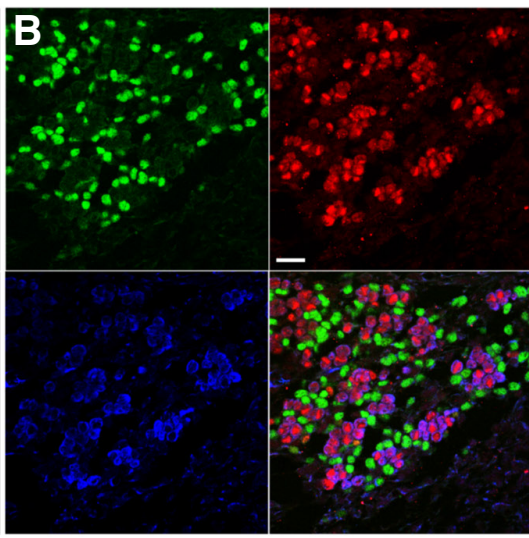

D
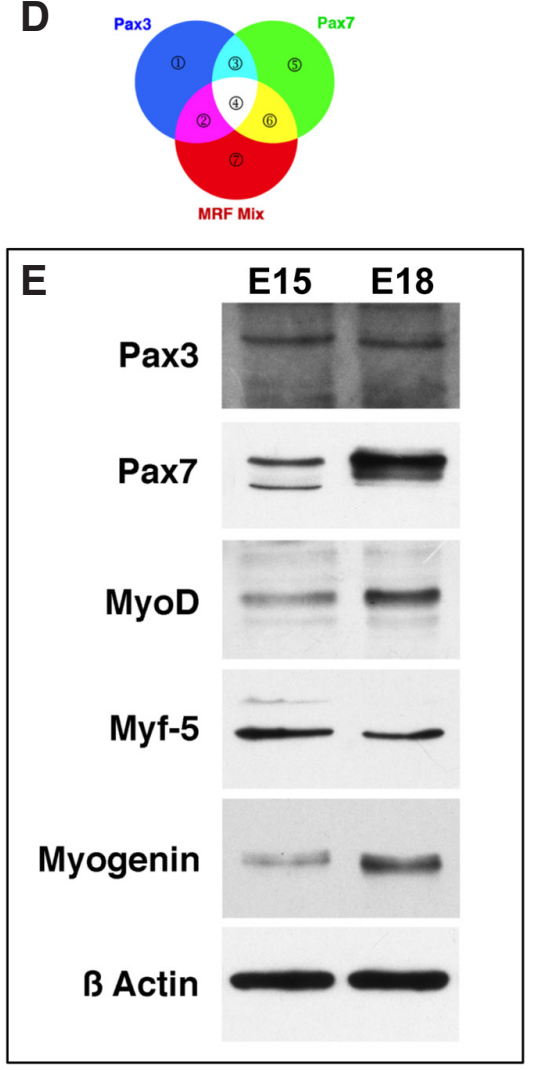
ted precursors, and to quantify the sizes of each cell population at various time points during myogenesis.

\section{Results}

Three communities of Pax3, Pax7 and MRF expressing cells were identified at all ages examined

Previous studies demonstrated that all limb muscles are generated from a group of several hundred cells that undergo a long-range migration from the limbadjacent somites prior to muscle formation while expressing one or more of Pax3, Pax7 or myogenic regulatory factors (MRFs) (Christ and Brand-Saberi, 2002, Tajbakhsh, 2003, Tajbakhsh, 2005). In order to identify the myogenic stem cell communities in the developing limb muscle isolated mononucleated cells from the rat TA and EDL muscles at E14-19 were triple-immunolabelled and quantified. Muscle lysates were used for western blots.

Images of the $\mathrm{Pax}^{+} \mathrm{Pax}^{+}$and $\mathrm{MRF}^{+}$cells presented as 7 overlapping or mutually exclusive subpopulations in cell isolates (Fig. 1A) and cross sections (Fig. 1B) of the developing muscle at primary (Fig.1B) and secondary (Fig. 1A) myogenesis. The intracellular protein expression patterns of the 7 subpopulations are demonstrated in Fig. 1C. A Venn diagram (Fig. 1D) illustrates the 3 general communities of Pax3, Pax7 and MRF expressing cells and how they overlap resulting in 7 subpopulations namely, Pax3, Pax7, MRF, Pax3/Pax7, Pax3/MRF, Pax7/MRF and Pax3/ Pax7/MRF. Representative Western blots of muscle lysates from E15 and E18 embryos verified the specificity of the antibodies used for identification of the cell populations (Fig. 1E). Using the intracellular protein expression patterns, myogenic stem cells at various developmental stages were identified and an increase of Pax7 expression suggested the active proliferation of these cells occurs during secondary myogenesis. The myogenic cells were also undergoing differentiation, as marked by increase in MyoD and myogenin expression levels.

Sizes of Pax3 and MRF communities remain constant during myogenesis while that of the Pax7 community gradually increases and peaks at the late stage of myogenesis

If we assume the migratory somitic cells as the main, if not sole source of limb muscle progenitors, then the subpopulations identified in this study must be derived from these migratory cells but expanded at different times (Dudley et al., 2002, Sun et al., 2004, Tajbakhsh, 2003).

Quantification of Pax3, Pax7 and MRF communities of mononucleated cells showed that approximately $62 \%$ were myogenic cells. A slight increase was observed at E17, with $77 \%$ being myogenic cells (Table 1 ). These percentages remained unchanged throughout primary and secondary myogenesis. During primary myogenesis, the majority of cells expressed Pax3 (58\% of counted cells) or MRFs (45\%), whereas only $5 \%$ of

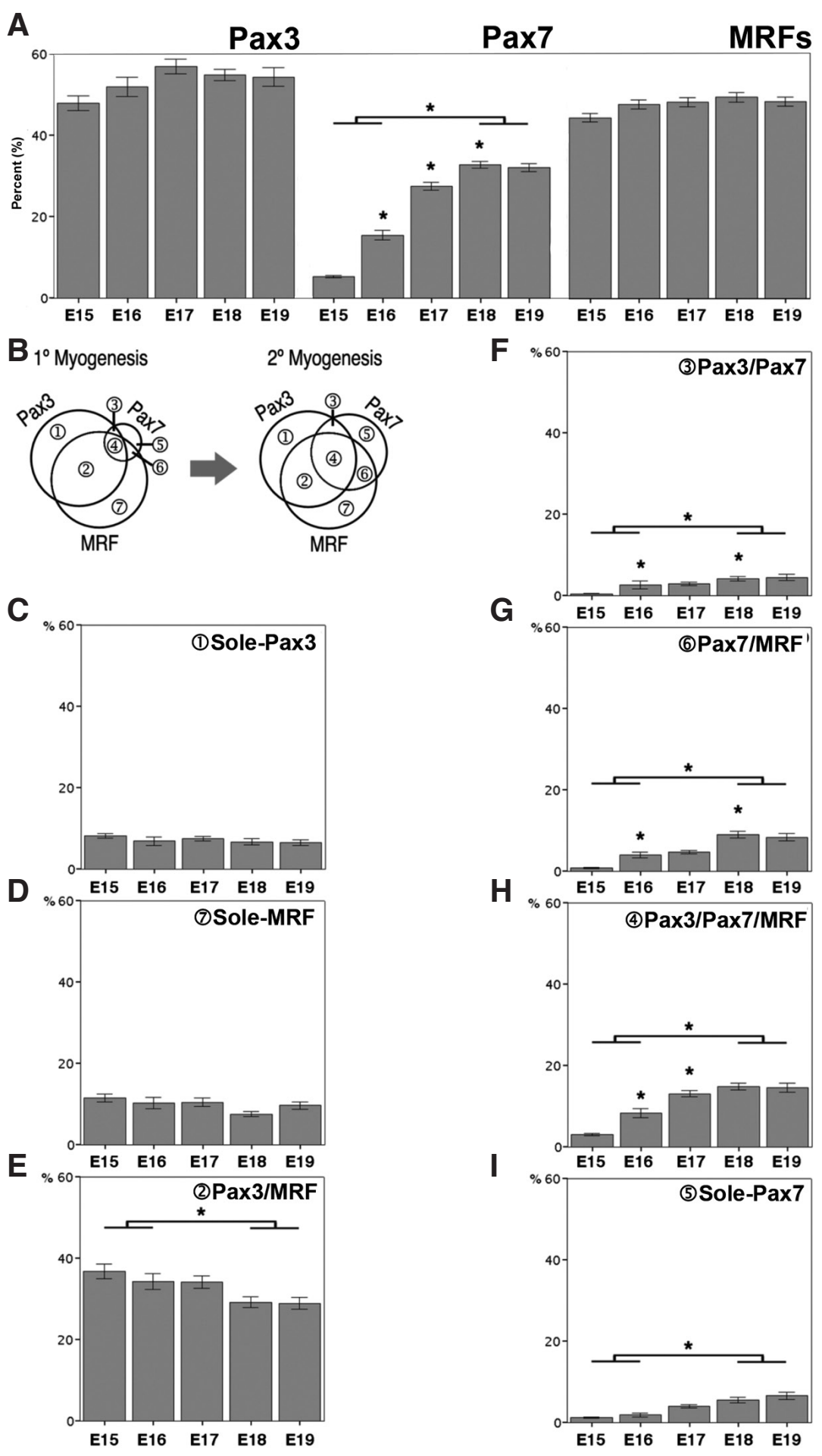

Fig. 2. Quantitative analyses of the 7 subpopulations of isolated cells. Analyses of cells isolated from E15 - E19 embryos show the overall sizes of (A) Pax3 ${ }^{+}$and $\mathrm{MRF}^{+} \mathrm{com}-$ munities remain constant during myogenesis while that of $\mathrm{Pax} 7^{+}$population increases significantly. (B) Venn diagram summarizing the quantitative changes of 3 communities and 7 subpopulations between primary $\left(1^{\circ}\right)$ and secondary $\left(2^{\circ}\right)$ myogenesis. Analyses of the 7 subpopulations revealed that the sizes of (C) (1) sole-Pax $3^{+}$and (D) (7) sole-MRF+ subpopulations remained constant while that of (E) (2) $\mathrm{Pax}^{+} \mathrm{MRF}^{+}$subpopulation gradually but significantly decreased during myogenesis. In contrast, all four Pax7 co-expressing subpopulations, (F) (3) $\mathrm{Pax}^{+} / \mathrm{Pax} 7^{+}$, (G) (6) $\mathrm{Pax}^{+} / \mathrm{MRF}^{+}$, (H) (4) $\mathrm{Pax}^{+} / \mathrm{Pax}^{+} / \mathrm{MRF}^{+}$and (I) (5) sole Pax $7^{+}$showed a significant increase in their sizes during myogenesis. ${ }^{*} p<0.05$ ANOVA (Single Factor). Bars represent mean \pm S.E.M. 
the cells expressed Pax7 (Fig. 2A). At E18, the Pax7+ expressing cell population increased to $33 \%$, which were 6 fold greater than the same population at E15. The most significant expansion of this community occurred just prior to the start of secondary myogenesis (E17). In contrast, the proportions of Pax3 expression and MRF cell communities were maintained at almost the same level throughout primary and secondary myogenesis (Fig. 2B).

Analyses of the 7 subpopulations revealed more dynamic changes as the sizes of sole-Pax3 (Fig. 2C) and sole-MRF (Fig. 2D) subpopulations remained constant, whereas Pax3/MRF (Fig. $2 \mathrm{E})$ expressing cells significantly decreased as myogenesis progressed. In contrast, all Pax7 co-expressing subpopulations Pax3/ Pax7 (Fig. 2F); Pax7/MRF (Fig. 2G); Pax3/Pax7/MRF (Fig. 2H) and sole-Pax7 (Fig. 2I) showed a significant increase in their sizes at the later stage of myogenesis. Subpopulations co-expressing $\mathrm{Pax} 7$ showed a gradual but significant increase in their relative number while those that co-express Pax3 and MRF remained constant throughout myogenesis.

The proportion of Pax3 co-expressing cells decreased from $71 \%$ at E15 to $48 \%$ at E19, whereas the proportion of Pax3/Pax7 and Pax 7 co-expressing cells started at about $6 \%$ and $2 \%$ at E15 and then increased about 4 and 8 times, respectively, over the period of primary and secondary myogenesis (Table 1 ).

\section{p38 MAP kinase inhibitor (SB202190)-treated subpopulations undergo different quantitative changes during myogenesis}

To test if perturbing the regulatory pathway for myogenic differentiation will affect the kinetics of myogenic stem cell communities, SB202190 was used to inhibit p38 at the peak of p38 activity at the beginning of secondary myogenesis (Weston et al., 2003, Wu et al., 2000).

Western blot analysis showed unchanged levels of p38 following $\mathrm{SB}$ treatment compared to its control ( $\mathrm{N}$; Fig. $3 \mathrm{~A})$. The levels of phosphorylated p38 (phospho-p38) however were significantly reduced following treatment exhibiting the effectiveness of SB202190 inhibition on p38 phosphorylation. Protein levels of MyoD, Myf5 and myogenin were all significantly reduced in samples treated with SB compared to the untreated controls. In contrast the protein levels of Pax 3 and Pax7 remain unchanged. The reduced expression levels of MRFs upon inhibition of p38 MAPK activity suggest that this particular signalling pathway interferes with MRF expression in embryonic limb muscle and subsequent differentiation.

The relative sizes of the myogenic cell communities after SB202190 treatment showed that the (1) sole-Pax3 subpopulation remained unchanged (Fig. 3B). The (2)Pax3-MRF cell population decreased to $21.9 \%$ compared to $29.4 \%$ in the control. The size of the (3) Pax3/Pax7 subpopulation decreased to $1.7 \%$ compared to

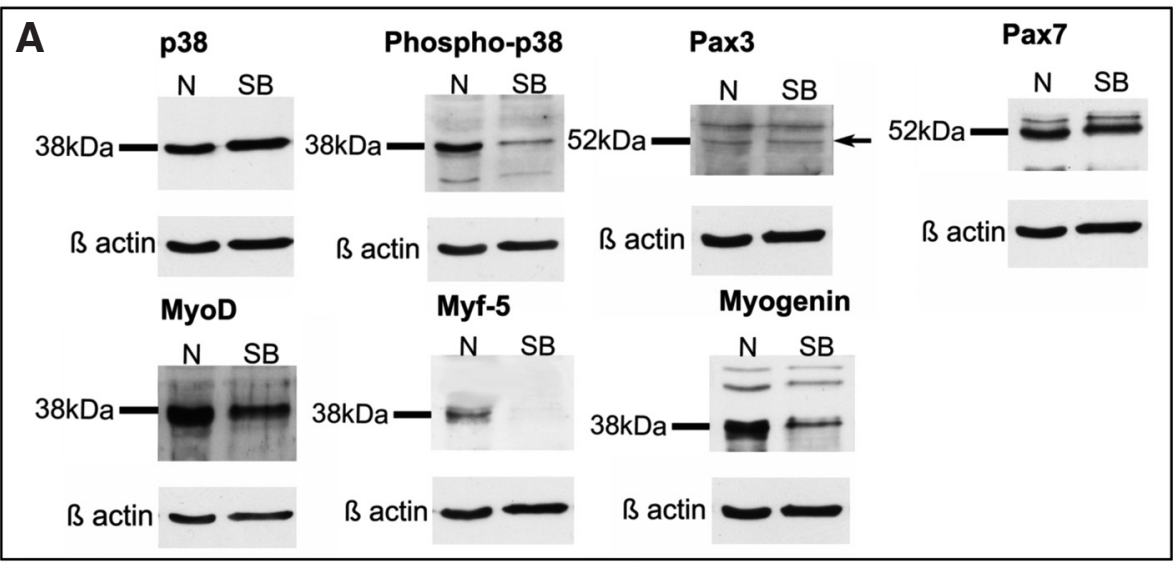

B
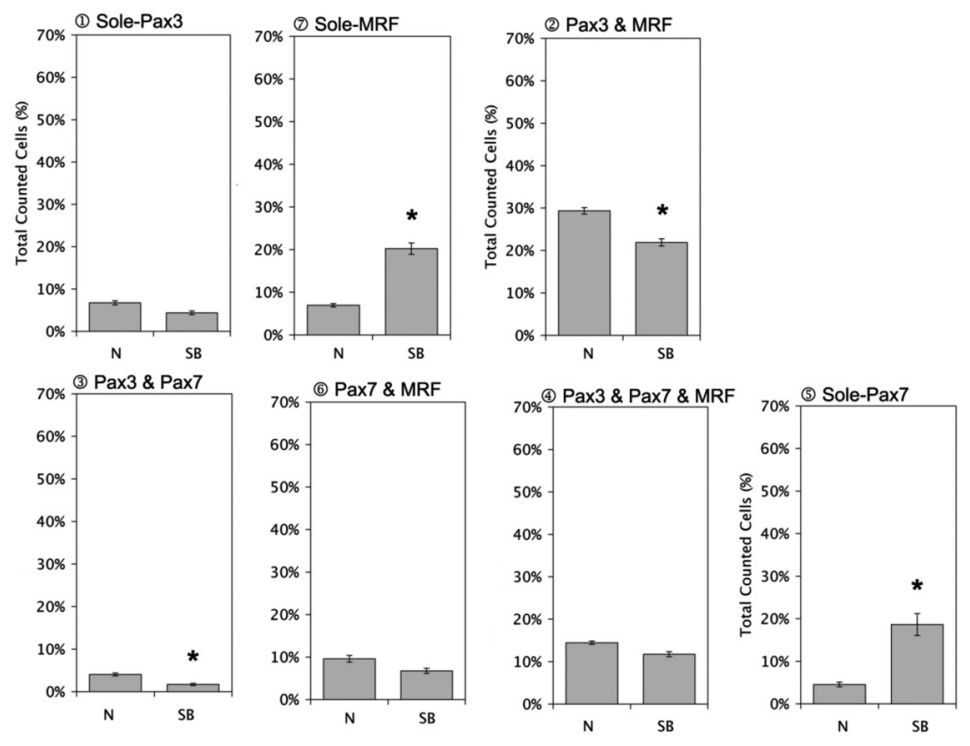

$4 \%$ in the untreated controls. The (5)sole-Pax 7 and the (7)sole-MRF populations showed a three fold increase following SB treatment. The size of the (5) sole-Pax7 subpopulation increased to $18.6 \%$ compared to $4.6 \%$ in the control, while the (7) sole-MRF subpopulation increased from $20.2 \%$ from $7 \%$ in the control. When the sizes of the (4)Pax3/Pax7/MRF and the (6) Pax7/MRF subpopulations were analysed no statistical differences were seen.

Such a change in the sizes of the different cell subpopulations suggests that inhibition of the p38 activity disrupted the existing balance amongst the subpopulations of myogenic cells.

Fig. 3. Western blot analyses of muscle lysates from embryos injected with SB202190. (A) Western blots using anti-p38, -phospho-p38, -Pax3, $-P a x 7,-M y o D,-m y f-5$ and -myogenin antibodies on muscle lysates from E18 embryos that were either untreated $(N)$ or injected with SB202190 (SB). Anti- $\beta$-actin was used as a loading control. (B) Quantitative analyses of 3 communities and 7 subpopulations from cells isolated from untreated (N) or SB treated embryos as a percentage. The overall size of $\mathrm{Pax}^{+}$population decreased significantly whilst that of $\mathrm{Pax}^{+}$and $\mathrm{MRF} \mathrm{F}^{+}$communities remained unchanged following injection of SB. Analyses on the 7 subpopulations revealed that the sizes of (7) sole-MRF+ and (5) sole Pax $7^{+}$subpopulations increased significantly following SB202190 treatment while that of (2) $\mathrm{Pax}_{3}{ }^{-} \mathrm{MRF}^{+}$and (3) $\mathrm{Pax}^{+} /$ $\mathrm{Pax}^{+}$subpopulations significantly decreased. The sizes of (1) sole-Pax3+, (6) Pax $7^{+} / \mathrm{MRF}^{+}$and (4) $\mathrm{Pax}^{+}$ $/ P a x 7^{+} / M^{\prime} F^{+}$subpopulations remained constant following SB treatment. ${ }^{*} p<0.05$ ANOVA (Single Factor). Bars represent mean + S.E.M. 


\section{Discussion}

This study identifies the relative number of $\mathrm{Pax} 3^{+}, \mathrm{Pax}^{+}$and $\mathrm{MRF}^{+}$ cells at different time points during development and reveals changes of their proportions between primary and secondary myogenesis. The community effect results from an interaction amongst a group of precursor cells regulating their differentiation in a synchronised fashion. Cell density must have increased beyond a certain level to instigate the community effect; therefore any alteration in cell proportions could correlate with a change in cell community. This study demonstrates the presence of myogenic stem cell communities, namely, $\mathrm{Pax}^{+}, \mathrm{Pax}^{+}$and $\mathrm{MRF}^{+}$, as well as their overlapping and mutually exclusive subpopulations throughout development in rat hindlimb muscles. Quantitative analyses identified that the sizes of Pax3 and MRF compartments remained constant. Disruption of the p38 regulatory pathway for myogenic differentiation resulted in the significant increase in the proportion of $\mathrm{MRF}^{+}$and $\mathrm{Pax} 7^{+}$expressing cells. These quantitative data provides a basis for us to better understand the myogenic stem cell kinetics during myogenesis.

In the developing rat TA and EDL muscles, formation of the primary myotubes occurs between E14 and E16, whereas formation of secondary myotubes begins after E17 (Wilson and Harris, 1993) and there is a one day period in which no new myotubes are formed. However, studies on the birthdate of myonuclei indicates that myotubes in the EDL and TA muscles were continuously absorbing new nuclei throughout the whole myogenesis and there was no gap between the primary and secondary myogenesis (Harris et al., 1989, Zhang and McLennan, 1995). The results from this study show that the relative percentage of overall mononucleated myogenic cells remained constant during myogenesis, and that a $10 \%$ increase occurred just prior to the start of secondary myogenesis (E17). It was perceivable that the entire mononucleated myogenic cell community must be significantly expanded prior to secondary myogenesis in order to meet the requisite number of cells for development because the average body weight of the embryos steadily increased from E15 to E19 (Table 2) and the number of the terminally differentiated myoblasts gradually and significantly increased throughout myogenesis (Zhang and McLennan, 1995).

Both Pax3 and Pax7 play vital roles in the appearance of a variety of tissues during development but play a major role in the development of skeletal muscle (Buckingham and Relaix, 2015). Expression of Pax3 or Pax7 in satellite cells or myoblasts resulted in an increased proliferative rate but dominant-negative expression led to a reduction of cell division (Collins et al., 2009). It was notable that Pax3 cells were not only present throughout myogenesis, but also, that the relative size of the population was maintained as a substantial proportion (approximately $50 \%$ ) of total cells that were not depleted by the end of myogenesis. In contrast, the overall Pax7 pool, which was minuscule at the beginning, showed a continuous and significant increase reaching its peak during secondary myogenesis. The constant relative size of the Pax3 pool following the
TABLE 1

\section{PROPORTIONS (\%) OF TOTAL MYOGENIC POPULATIONS AMONG TOTAL COUNTED CELLS IN HIND LIMB BUDS (A) AND TA \& EDL MUSCLES (B)}

\begin{tabular}{|c|c|c|c|c|c|}
\hline A & E14 & E15 & E16 & & \\
\hline Myogenic pop & $43.4 \pm 1.9$ & $45.5 \pm 1.9$ & $39.3 \pm 1.5$ & & \\
\hline From 1 Set & $\mathrm{n}=45$ & $\mathrm{n}=29$ & $\mathrm{n}=36$ & & \\
\hline B & E15 & E16 & E17 & E18 & E19 \\
\hline Myogenic pop & $61.9 \pm 2.2$ & $68.0 \pm 2.5$ & $76.5 \pm 1.7$ & $76.8 \pm 1.6$ & $78.8 \pm 2.1$ \\
\hline From 1 Set & $\mathrm{n}=54$ & $\mathrm{n}=30$ & $\mathrm{n}=60$ & $\mathrm{n}=52$ & $\mathrm{n}=36$ \\
\hline
\end{tabular}

Mean percentages of counted immunolabelled cells from 1 or more sets (each set comprised of 3 slides from 3 different litters) for each age group. $n=$ number of grid squares counted from all slides. The cells are counted from staining combination; Pax3, Pax7 and MRF. Total cells are all cells visible using phase microscopy. Data are expressed as mean + SEM.

arrival of a limited number of Pax3 migratory ancestors within the growing limb indicated a constant rate of proliferation was achieved. Reports showed that the resident Pax3 and Pax7 cells in the trunk muscles did not co-express the endothelial marker PECAM or connective tissue marker TCF4 (Kassar-Duchossoy et al., 2005, Relaix et al., 2005). Suggesting that the Pax3 expressing cells in the limb muscles are unlikely to give rise to endothelial or connective tissue lineage. Therefore the extent of non-myogenic contribution from the constantly proliferating pool of $\mathrm{Pax} 3$ cells identified in this study is likely to be negligible.

Pax3 was found in the satellite cells of a few specific muscle groups only (Buckingham et al., 2003), in contrast to Pax7, which has been found in the satellite cells of most skeletal muscles in mice (Seale et al., 2000). In the rat muscle, the Pax3 cell pool contained two subpopulations of either $\mathrm{MRF}^{+}$or MRF-. Our results are in agreement with reports that the $\mathrm{Pax} 3 / \mathrm{Pax} 7$ population that MRF- was found as resident muscle progenitors throughout development in both the trunk and limbs (Relaix et al., 2005). Interestingly, both the overall sole-Pax3 ${ }^{+}$pool and the Pax3/MRF populations were not depleted by the end of myogenesis but remained steady at around $30 \%$. This could represent an actively differentiating population supplying cells for tissue growth, as Pax3 is known to be present in the mitotically active cells (Relaix and Zammit, 2012).

Furthermore, the majority of myogenic cells in the limbs were derived from the migration of somitic cells expressing Pax3 only. Although there is no evidence to exclude the possibility that nonsomitic stem cells in the limb contribute to myogenic cells, we presume that quantitatively such contribution would be minimal. Therefore, the cell supply for the Pax3 compartment was most likely derived from the symmetric self-replication of the somitic Pax3 cells. On the other hand, cells exiting the Pax3 compartment could undergo one of three fates; apoptosis, enter the Pax $7^{+}$, or the $\mathrm{MRF}^{+}$compartments. The stem cell population is maintained by the self-renewing proliferation of satellite cells. The performance of satellite cells is stringently regulated via intrinsic and extrinsic

TABLE 2

MEAN BODY WEIGHT (G) OF EMBRYOS FROM EACH AGE AND EXPERIMENTAL GROUP

\begin{tabular}{cccc} 
& \multicolumn{3}{c}{ Entire Limb Buds Collected } \\
\cline { 2 - 4 } & E14 & E15 & E16 \\
\hline Total & $0.153 \pm 0.002$ & $0.324 \pm 0.004$ & $0.602 \pm 0.010$ \\
& $(n=44)$ & $(n=48)$ & $(n=53)$ \\
\hline
\end{tabular}

\begin{tabular}{|c|c|c|c|c|c|}
\hline E14 & E15 & E16 & E17 & E18 & E19 \\
\hline- & $\begin{array}{c}0.342 \pm 0.005 \\
(n=38)\end{array}$ & $\begin{array}{c}0.601 \pm 0.005 \\
(n=48)\end{array}$ & $\begin{array}{c}0.939 \pm 0.013 \\
(n=47)\end{array}$ & $\begin{array}{c}1.557 \pm 0.018 \\
(n=45)\end{array}$ & $\begin{array}{c}2.363 \pm 0.034 \\
(n=51)\end{array}$ \\
\hline
\end{tabular}


factors within the muscle stem cell microenvironment. Feedback does not require cell-cell contact and may be instead achieved by paracrine signals that influence differentiation outcomes as a robust control mechanism to maintain homogeneous gene expression across a group of cells.

A lineage analysis showed that $\mathrm{Pax} 3^{+}$somatic cells gave rise to $\mathrm{Pax} 7^{+}$cells as well as embryonic myogenic cells whilst, $\mathrm{Pax} 3^{+} / \mathrm{Pax} 7^{+}$ cells contributed to foetal myogenic cells in the limb (Hutcheson et al., 2009). Such observations coincide with our own of the increased proportion of (3) Pax3/Pax $7^{+}$compartment. Furthermore, amplification of the Pax7 compartment during myogenesis is likely to provide an increased pool of determined but undifferentiating myogenic progenitors in preparation for both secondary and postnatal muscle growth. The continued presence of the Pax3/ MRF subpopulation may also have an implication on satellite (or adult muscle progenitor) lineage, as Pax3 cells were found in the interstitial space distinct from the Pax7 sub-lamina satellite cells (Kuang et al., 2006). These results support this observation that this population is present throughout myogenesis.

Interestingly, the proportion of Pax3 cells that co-express Pax7 increased during myogenesis, while those that co-express MRF decreased. This shift implies that more $\mathrm{Pax}^{+}$cells may move to the Pax7 compartment as myogenesis progresses. Such a shift may serve to accommodate secondary myogenesis, during which, a large number of muscle cells are demanded not only for the formation of new myotubes but also for the growth of the existing myotubes. A recent study showed changes in the cycling status of committed progenitor cells as the undifferentiated resident progenitor cells that expressed Pax7 represented a slow-cycling pool, whereas Pax3/Pax7/Myf5 committed progenitors co-existed as a fast-cycling population suggesting that the fraction of Pax7/ Myf5 cells were reduced during the foetal stage (E15) (Picard and Marcelle, 2013). Cells within the muscle interact with each other activating genes in homogeneous cell groups typifing the community effect as a widespread developmental mechanism that is used to increase homogeneity in embryonic tissues.

Inhibition of p38 phosphorylation disrupted the normal community kinetics and propagation of the myogenic stem cell communities and significantly affected the developmental progression of the mononucleated muscle cells. Researchers have previously observed malformation in the limbs (de Angelis et al., 2005) suggesting that inhibition of pp38 may result in defective myogenesis. The consequential changes not only in muscle specific protein levels of MRFs but also in the significant increase in the proportion of (7)sole-MRF ${ }^{+}$and (5)sole-Pax7, and in contrast, (2) Pax3-MRF and (3) Pax3-Pax7 subpopulations significantly decreased. This expansion in the proportion of MRF+ and Pax7+ cells would be a direct consequence of the inhibition of $\mathrm{p} 38$. Thus providing direct evidence to indicate that the regulatory environment, such as the p38 intracellular pathway has significant impact on the behaviour of the mononucleated muscle cells in the developing limb muscle.

The majority of the cells in the $\mathrm{MRF}^{+}$compartment will be progenitors undergoing differentiation (Manceau et al.). However, it should be noted that heterogeneity exists among the members of MRF constituents of the compartment. The MRF population contained decreasing Pax3 and increasing Pax7 myogenic subpopulations, which may constitute a dynamically maintained niche for the muscle stem cells. The overall $\mathrm{MRF}^{+}$community was maintained at a constant size during myogenesis. Such compensation may be because of a direct lineage progression from Pax3 to Pax7 cells (Kassar-Duchossoy et al., 2005, Relaix et al., 2005), and/or due to increasing number of Pax3/Pax7 and sole-Pax7 cells which start to co-express MRFs. Further analysis showed that the Myf5 cell subpopulation was the main constituent of the MRF population at about $40 \%$ throughout myogenesis. The increasing pattern of MyoD ${ }^{+}$cells within the steady Myf5 pool implied that the demand for differentiation increased during secondary myogenesis, thus requiring more MyoD activated cells. The Myf5 population generally proliferates whilst the MyoD population is more likely to differentiate. This rate of differentiation decreases and stabilises as more cells occupy the muscle with growth. The dynamic interaction and balance among cells at different developmental stages must be influencing kinetic influences to one another as individual cells and/or as cell compartments.

It appears pertinent to consider whether the dynamically maintained proportions of each mononucleated cell subpopulation at various developmental stages may constitute important components of the stem cell niche. Slight differences in timing are seen across the species, in that migrating muscle progenitors in the limb mesenchyme co-express both transcription factors Pax3 and $\mathrm{Pax} 7$ in the chick, while Pax7 expression is delayed by about a day after that of Pax3 in the mouse (Picard and Marcelle, 2013). Cell populations expand due to either the increased proliferation of cells in that population or because differentiation causes cells to move from one subpool to another. Any changes in cell density may affect the absolute number of myogenic cells over time and the consequent overall development of the limb.

The quantitative analysis on mononucleated cells of various developmental stages reported in this study may provide valuable insights in understanding the mechanisms behind the myogenic fate determination in the rat. Moreover, the proposed concept of community effect among dynamically balanced cell populations of various developmental stages as a component of stem cell niche during normal development may carry significant impact on stem cell research.

\section{Conclusion}

This study demonstrates the presence of myogenic stem cell communities, namely, $\mathrm{Pax}^{+}, \mathrm{Pax}^{+}$and $\mathrm{MRF}^{+}$, as well as their overlapping and mutually exclusive subpopulations throughout development in rat hindlimb muscles. Quantitative analyses on the relative sizes of each subpopulation revealed that distinctive cell-community kinetic patterns were either maintained or emerged during muscle development. Upon abrupt disruption in the regulatory pathway for myogenic differentiation, the established kinetic patterns among subpopulations were significantly altered. It implies that a community effect involving dynamic interactions among stem, progenitor and differentiating cell populations may play a crucial role in the correct maintenance and propagation of stem cells during organogenesis in higher vertebrates adding to our knowledge of the dynamic processes of communities in development.

\section{Materials and Methods}

\section{Animals and tissue preparation}

All experiments were performed under the approval of the University of Otago Animal Ethics Committee. A total of 374 embryos (an average of $15.6 \pm 0.5$ embryos per litter) from 24 pregnant Wistar rats (ages 8 to 10 
weeks old) were used. Pregnancies were determined by the presence of copulation plugs (embryonic day zero: E0). The embryos were extracted from the pregnant rats between gestation day E14 and E19 and decapitated after body weights were recorded (Table 2). These timepoints were chosen because gatherings of undifferentiated cells marking the site of formation of the muscles were seen on embryonic day 15 (E15). Primary myotubes appear on E16 and reach stability by day E17. E15-16 signifies primary myogenesis, E18-19 signifies secondary myogenesis and E17 signifies the one day gap (Harris et al., 1989).

In a second set of experiments, pregnant rats (E17) were injected intraperitoneally (i.p.) with either SB202190 (A.G. Scientific Inc., Ca, USA) a potent p38 MAPK inhibitor ( 3 doses of $5 \mathrm{mg}$ each over $24 \mathrm{~h}$ ) or with dimethyl sulfoxide (DMSO) vehicle control (de Angelis et al., 2005). A total of 42 and 43 embryos (E18) were collected respectively, the left legs dissected, cryosectioned $(10 \mu \mathrm{m})$ and stored at $-20^{\circ} \mathrm{C}$ until required. Tissue was also lysed and the myogenic populations isolated for Western blot analysis and mononucleated cell immunostaining and quantification.

\section{Mononucleated cell isolation}

Tibialis anterior (TA) and extensor digitorum longus (EDL) muscles were harvested. Tissues were placed in sterile Hank's Balanced Salt Solution (Life Technologies, NZ) and digested in $0.05 \%$ trypsin for 15 mins at $37^{\circ} \mathrm{C}$ in a $5 \% \mathrm{CO}_{2}$ incubator. Following trypsin inactivation with fresh growth media (DMEM with 10\% FCS; Gibco), the contents were filtered through a 150 $\mu \mathrm{m}$ pore mesh. Mononucleated cells were washed twice by centrifugation at $175 \mathrm{~g}$ for 10 mins, resuspended in $0.1 \mathrm{M} \mathrm{PBS}$, air-dried onto slides and stored at $-20^{\circ} \mathrm{C}$ until required.

\section{Immunocytochemistry}

Sections or isolated cells were fixed in $4 \%$ paraformaldehyde followed by incubation in $0.1 \mathrm{M}$ glycine in $0.1 \mathrm{M}$ PBS to stop fixation. The slides were incubated in either goat or donkey serum (Sigma, Mo, USA). Three primary antibodies each raised from different species were used. The antibodies were diluted in $1 \%$ bovine serum albumin and $0.15 \%$ Tween-20 in $0.1 \mathrm{M}$ PBS and incubated overnight in a humidified chamber. Slides were incubated in combinations of either; anti-mouse Alexa 488, anti-rabbit Alexa 568 or anti-goat Alexa 633 (Life Technologies) and mounted in Vectashield (Vector). Slides were viewed using a LSM510 confocal laser-scanning microscope (Carl-Zeiss-Strasse, Oberkochen, $\mathrm{Ge}$ ) with Argon and HeNe lasers that provided excitation laser lines at $488 \mathrm{~nm}, 543 \mathrm{~nm}$ and $633 \mathrm{~nm}$. ImageJ (National Institutes of Health, MD, USA) was used to set consistent thresholding across all images. The entire slide was randomly systematically scanned and the numbers of positively labelled cells were counted using manual stereological techniques. Total cells were all cells visible using phase microscopy.

Primary antibodies used were as follows; mouse monoclonal antibodies against Pax7 at 1:50, myogenin F5D at 1:50, neonatal F59 at 1:100 (Developmental Studies Hybridoma Bank (DSHB), lowa, USA), MyoD 5.8A (BD Biosciences) at 1:100 and embryonic fast MY32 (Sigma) at 1:400. Rabbit polyclonal antibodies against Myf5 at 1:400, MyoD M-318 at 1:100 and myogenin M-225 (Santa Cruz, TX, USA) at 1:100. Goat polyclonal antibody against Pax3 (Abcam, MA, USA) at 1:400. No single MRF marked all of the myogenic cells, as shown by the existence of singly labelled cells in all of the double labelling. Thus, in order to mark all the myoblasts, a mixture of anti-MRF was adopted for the study containing $\alpha$-Myf5, $\alpha-M y o D$ and $\alpha$-Myogenin.

\section{Western Blot analyses}

For the analysis of protein expression, muscle samples were separated on a $15 \%$ polyacrylamide gel and the proteins transferred to PVDF (Biorad, $\mathrm{Ca}$, USA). The membrane was probed with primary antibodies diluted in Tris buffered saline (TBS) with $0.1 \%(\mathrm{v} / \mathrm{v})$ Tween-20 and $0.5 \%(\mathrm{w} / \mathrm{v})$ milk powder. Membranes were incubated with horseradish peroxidase-conjugated secondary antibodies before detection of antibody binding by chemiluminescence (Amersham). The membranes were reprobed for anti- $\beta$-actin to check protein loading. Band intensity was measured using a BioRad imaging densitometer and quantified using Molecular Analyst software.

Antibodies used were as follows; mouse monoclonal antibodies against Pax7 at 1:1000 myogenin F5D at 1:500 (DSHB) and MyoD 5.8A at 1:1000 (BD Biosciences). Rabbit polyclonal antibodies against Myf5 at 1:1000, MyoD M-318 at 1:1000 and myogenin M-225 (Santa Cruz, TX, USA) at 1:500. p38MAPKinase at 1:1000 and phosphorylated p38MAPKinase (Cell Signalling, USA) at 1:1000. Goat polyclonal antibody against Pax3 (Abcam, MA, USA) at 1:2000. Secondary antibodies were either; anti-mouse $\lg G$ (Sigma) at 1:2000, anti-rabbit lgG (Sigma) at 1:2000 or anti-goat IgG (Santa Cruz) at 1:2000.

\section{Statistical analysis}

Minitab Statistical Software (Sydney, Australia) was used to perform statistical analyses for Western blots. After the data was plotted for the Normality Test, the Andersons-Darling Test was used to determine whether the data was normally distributed $(p<0.05)$. Data were analysed with SAS ${ }^{\circledR}$ (SAA Institute Inc., NC, USA), tested for Poisson regression or negative binomial regression. The observed changes in the relative sizes of affected subpopulations were confirmed using the Principal Component Analysis. Cluster Analysis used algorithms to sort the cell subpopulations with maximum degree of association into respective categories.

\section{Acknowledgements}

We thank Dr. Vicki Livingstone (Department of Preventive and Social Medicine, University of Otago) and Professor Paul Smith (Department of Pharmacology, University of Otago) for statistical analyses, and Dr. Yiwen Zheng (Department of Pharmacology, University of Otago) with her kind help with western blot analyses.

\section{References}

AUBIN-HOUZELSTEIN, G., BERNEX, F., ELBAZ, C. and PANTHIER, J.J. (1998). Survival of patchwork melanoblasts is dependent upon their number in the hair follicle at the end of embryogenesis. Dev Biol 198: 266-276.

BIRESSI, S., TAGLIAFICO, E., LAMORTE, G., MONTEVERDE, S., TENEDINI, E., RONCAGLIA, E., FERRARI, S., FERRARI, S., CUSELLA-DE ANGELIS, M.G., TAJBAKHSH, S. et al., (2007). Intrinsic phenotypic diversity of embryonic and fetal myoblasts is revealed by genome-wide gene expression analysis on purified cells. Dev Biol 304: 633-651.

BOBER, E., FRANZ, T., ARNOLD, H.-H., GRUSS, P. and TREMBLAY, P. (1994). Pax-3 is required for the development of limb muscles: a possible role for the migration of dermomyotomal muscle progenitor cells. Development 120:603-612.

BRAUN, T., RUDNICKI, M.A., ARNOLD, H.H. and JAENISCH, R. (1992). Targeted inactivation of the muscle regulatory gene Myf- 5 results in abnormal rib development and perinatal death. Cell 71: 369-382.

BUCKINGHAM, M. (2003). How the community effect orchestrates muscle differentiation. BioEssays 25: 13-16.

BUCKINGHAM, M., BAJARD, L., CHANG, T., DAUBAS, P., HADCHOUEL, J., MEILHAC, S., MONTARRAS, D., ROCANCOURT, D. and RELAIX, F. (2003). The formation of skeletal muscle: from somite to limb. J Anat 202: 59-68.

BUCKINGHAM, M. and RELAIX, F. (2015). PAX3 and PAX7 as upstream regulators of myogenesis. Sem. Cell Dev. Biol. 44: 115-125.

CHRIST, B. and BRAND-SABERI, B. (2002). Limb muscle development. Int. J. Dev. Biol. 46: 905-914.

COLLINS, C.A., GNOCCHI, V.F., WHITE, R.B., BOLDRIN, L., PEREZ-RUIZ, A., RELAIX, F., MORGAN, J.E. and ZAMMIT, P.S. (2009). Integrated functions of Pax3 and $\mathrm{Pax} 7$ in the regulation of proliferation, cell size and myogenic differentiation. PLoS One 4: e4475.

COSSU, G., KELLY, R., DIDONNA, S., VIVARELLI, E. and BUCKINGHAM, M. (1995). Myoblast differentiation during mammalian somitogenesis is dependent upon a community effect. Proc. Natl. Acad. Sci. USA 92: 2254-2258.

DE ANGELIS, L., ZHAO, J., ANDREUCCI, J.J., OLSON, E.N., COSSU, G. and MCDERMOTT, J.C. (2005). Regulation of vertebrate myotome development by the p38 MAP kinase-MEF2 signaling pathway. Dev Biol 283: 171-179. 
DUDLEY, A.T., ROS, M.A. and TABIN, C.J. (2002). A re-examination of proximodistal patterning during vertebrate limb development. Nature 418: 539-544.

GURDON, J.B., KATO, K. and LEMAIRE, P. (1993a). The community effect, dorsalization and mesoderm induction. Curr Opin Genet Dev 3: 662-667.

GURDON, J.B., LEMAIRE, P. and KATO, K. (1993b). Community effects and related phenomena in development. Cell 75: 831-834.

HARRIS, A.J., DUXSON, M.J., FITZSIMONS, R.B. and RIEGER, F. (1989). Myonuclear birthdates distinguish the origins of primary and secondary myotubes in embryonic mammalian steletal muscles. Development 107: 771-784.

HASTY, P., BRADLEY, A., MORRIS, J.H., EDMONDSON, D.G., VENUTI, J.M., OLSON, E.N. and KLEIN, W.H. (1993). Muscle deficiency and neonatal death in mice with a targeted mutation in the myogenin gene. Nature 364: 501-506.

HUTCHESON, D.A., ZHAO, J., MERRELL, A., HALDAR, M. and KARDON, G. (2009). Embryonic and fetal limb myogenic cells are derived from developmentally distinct progenitors and have different requirements for beta-catenin. Genes Dev 23: 997-1013.

KARDON, G., CAMPBELL, J.K. and TABIN, C.J. (2002). Local extrinsic signals determine muscle and endothelial cell fate and patterning in the vertebrate limb. Dev. Cell 3: 533-545.

KASSAR-DUCHOSSOY, L., GAYRAUD-MOREL, B., GOMES, D., ROCANCOURT, D., BUCKINGHAM, M., SHININ, V. and TAJBAKHSH, S. (2004). Mrf4 determines skeletal muscle identity in Myf5:Myod double-mutant mice. Nature 431: 466-471.

KASSAR-DUCHOSSOY, L., GIACONE, E., GAYRAUD-MOREL, B., JORY, A., GOMES, D. and TAJBAKHSH, S. (2005). Pax3/Pax7 mark a novel population of primitive myogenic cells during development. Genes Dev 19: 1426-1431.

KUANG, S., CHARGE, S.B., SEALE, P., HUH, M. and RUDNICKI, M.A. (2006). Distinct roles for $\mathrm{Pax} 7$ and $\mathrm{Pax} 3$ in adult regenerative myogenesis. J Cell Biol172: 103-113.

LASSAR, A.B., SKAPEK, S.X. and NOVITCH, B. (1994). Regulatory mechanisms that coordinate skeletal muscle differentiation and cell cycle withdrawal. Curr Opin Cell Biol 6: 788-794.

MANCEAU, M., GROS, J., SAVAGE, K., THOMÉ, V., MCPHERRON, A., PATERSON B. and MARCELLE, C. MOSS, E.P. and LEBLOND, C.P. (1971). Satellite cells as ther source of nuclei in muscles of growing rats. Anat. Rec. 170: 421-436.

MOXHAM, C.M., TABRIZCHI, A., DAVIS, R.J. and MALBON, C.C. (1996). Jun Nterminal kinase mediates activation of skeletal muscle glycogen synthase by insulin in vivo. J Biol Chem 271: 30765-30773.

NIKOVITS, W., CANN, G.M., HUANG, R., CHRIST, B. and STOCKDALE, F.E. (2001). Patterning of fast and slow fibers within embryonic muscles is established independently of signals from the surrounding mesenchyme. Development 128:2537-2544.

ONTELL, M. (1978). Neonatal muscle: an electron microscopic study. Anat. Rec. 189: $669-690$.

OTT, M.O., BOBER, E., LYONS, G., ARNOLD, H. and BUCKINGHAM, M. (1991). Early expression of the myogenic regulatory gene, myf-5, in precursor cells of skeletal muscle in the mouse embryo. Development 111: 1097-1107.

PICARD, C.A. and MARCELLE, C. (2013). Two distinct muscle progenitor populations coexist throughout amniote development. Dev Biol 373: 141-148.

RELAIX, F., ROCANCOURT, D., MANSOURI, A. and BUCKINGHAM, M. (2004).
Divergent functions of murine Pax3 and pax7 in limb muscle development. Genes Dev. 18: 1088-1105

RELAIX, F., ROCANCOURT, D., MANSOURI, A. and BUCKINGHAM, M. (2005) A Pax3/Pax7-dependent population of skeletal muscle progenitor cells. Nature 435: $948-953$

RELAIX, F. and ZAMMIT, P.S. (2012). Satellite cells are essential for skeletal muscle regeneration: the cell on the edge returns centre stage. Development 139:2845-2856

ROSS, J.J., DUXSON, M.J. and HARRIS, A.J. (1987). Neural determination of muscle fibre numbers in embryomic rat lumbrical muscles. Development 100: 395-409.

SEALE, P., SABOURIN, L.A., GIRGIS-GABARDO, A., MANSOURI, A., GRUSS, P. and RUDNICKI, M.A. (2000). Pax7 is required for the specification of myogenic satellite cells. Cell 102: 777-786.

STOCKDALE, F.E. (1992). Myogenic cell lineages. Dev. Biol. 154: 284-298.

STUTTEM, I. and CAMPOS-ORTEGA, J.A. (1991). Cell commitment and cell interactions in the ectoderm of Drosophila melanogaster. Development Suppl 2: 39-46.

SUN, L., LIU, L., YANG, X.-J. and WU, Z. (2004). Akt binds prohibitin 2 and relieves its repression of MyoD and muscle differentiation. J. Cell Sci. 117: 3021-3029.

TAJBAKHSH, S. (2003). Stem cells to tissue: molecular, cellular and anatomical heterogeneity in skeletal muscle. Curr. Opin. Genet. Dev. 13: 413-422.

TAJBAKHSH, S. (2005). Skeletal muscle stem and progenitor cells: reconciling genetics and lineage. Exp. Cell Res. 306: 364-372.

WEINTRAUB, H., DAVIS, R., TAPSCOTT, D., THAYER, M., KRAUSE, M., BENEZRA R., BLACKWELL, T., TURNER, D., RUPP, R., HOLLENBERG, S. et al., (1991) The myoD gene family: Nodal point during specification of the muscle cell lineage. Science 251: 761-766

WESTON, A.D., SAMPAIO, A.V., RIDGEWAY, A.G. and UNDERHILL, T.M. (2003) Inhibition of p38 MAPK signaling promotes late stages of myogenesis. J. Cell Sci. 116: 2885-2893.

WILLIAMS, B.A. and ORDAHL, C.P. (1994). Pax-3 expression in segmental mesoderm marks early stages in myogenic cell specification. Development 120: 785-769.

WILSON, S.I. and HARRIS, A.J. (1993). Formation of myotubes in aneural rat muscles. Dev. Biol. 156: 509-518.

WU, Z., WOODRING, P.J., BHAKTA, K.S., TAMURA, K., WEN, F., FERAMISCO, J.R., KARIN, M., WANG, J.Y.J. and PURI, P.L. (2000). p38 and extracellular signal-regulated kinases regulate the myogenic program at multiple steps. Molec. Cell. Biol. 20: 3951-3964.

YASUO, H. and LEMAIRE, P. (1999). A two-step model for the fate determination of presumptive endodermal blastomeres in Xenopus embryos. Curr Biol9: 869-879.

ZAMMIT, P. and BEAUCHAMP, J. (2001). The skeletal muscle satellite cell: stem cell or son of stem cell? Differentiation 68: 193-204.

ZETSER, A., GREDINGER, E. and BENGAL, E. (1999). p38 mitogen-activated protein kinase pathway promotes skeletal muscle differentiation. Participation of the Mef2c transcription factor. J Biol Chem 274: 5193-5200.

ZHANG, M. and MCLENNAN, I.S. (1995). During secondary myotube formation, primary myotubes preferentially absorb new nuclei at their ends. Dev. Dyn. 204: 168 - 177.

ZHANG, M. and MCLENNAN, I.S. (1999). The myotubal origin of rat muscle fibres affects the extent of tenotomy-induced atrophy. J. Physiol. 519: 197-202. 


\section{Further Related Reading, published previously in the Int. J. Dev. Biol.}

Comparative expression analysis of $\mathrm{Pax} 3$ and $\mathrm{Pax} 7$ during mouse myogenesis

David Horst, Svetlana Ustanina, Consolato Sergi, Gregor Mikuz, Herbert Juergens, Thomas Braun and Eugene Vorobyov

Int. J. Dev. Biol. (2006) 50: 47-54

https://doi.org/10.1387/ijdb.052111dh

Myogenic potential of mouse primordial germ cells

Francesca-Gioia Klinger, Maria-Lucia Scaldaferri, Anna Di Carlo, Marta Baiocchi, Marcello Coletta, Giulio Cossu and Massimo De Felici

Int. J. Dev. Biol. (2003) 47: 303-305

http://www.intjdevbiol.com/web/paper/12755336

Changes in the proportion and number of $\operatorname{Pax}(7+\mathrm{ve})$ and MF20(+ve) myoblasts during chick myogenesis in the head and limb

Antonio S J Lee, Ming Zhang and Darrell J R Evans

Int. J. Dev. Biol. (2004) 48: 31-38

http://www.intjdevbiol.com/web/paper/15005572

\section{Limb muscle development}

Bodo Christ and Beate Brand-Saberi

Int. J. Dev. Biol. (2002) 46: 905-914

http://www.intjdevbiol.com/web/paper/12455628

A dynamic requirement for community interactions during Xenopus myogenesis Henrietta J Standley, Aaron M Zorn and John B Gurdon Int. J. Dev. Biol. (2002) 46: 279-283

http://www.intjdevbiol.com/web/paper/12068948

5 yr ISI Impact Factor $(2013)=2.879$
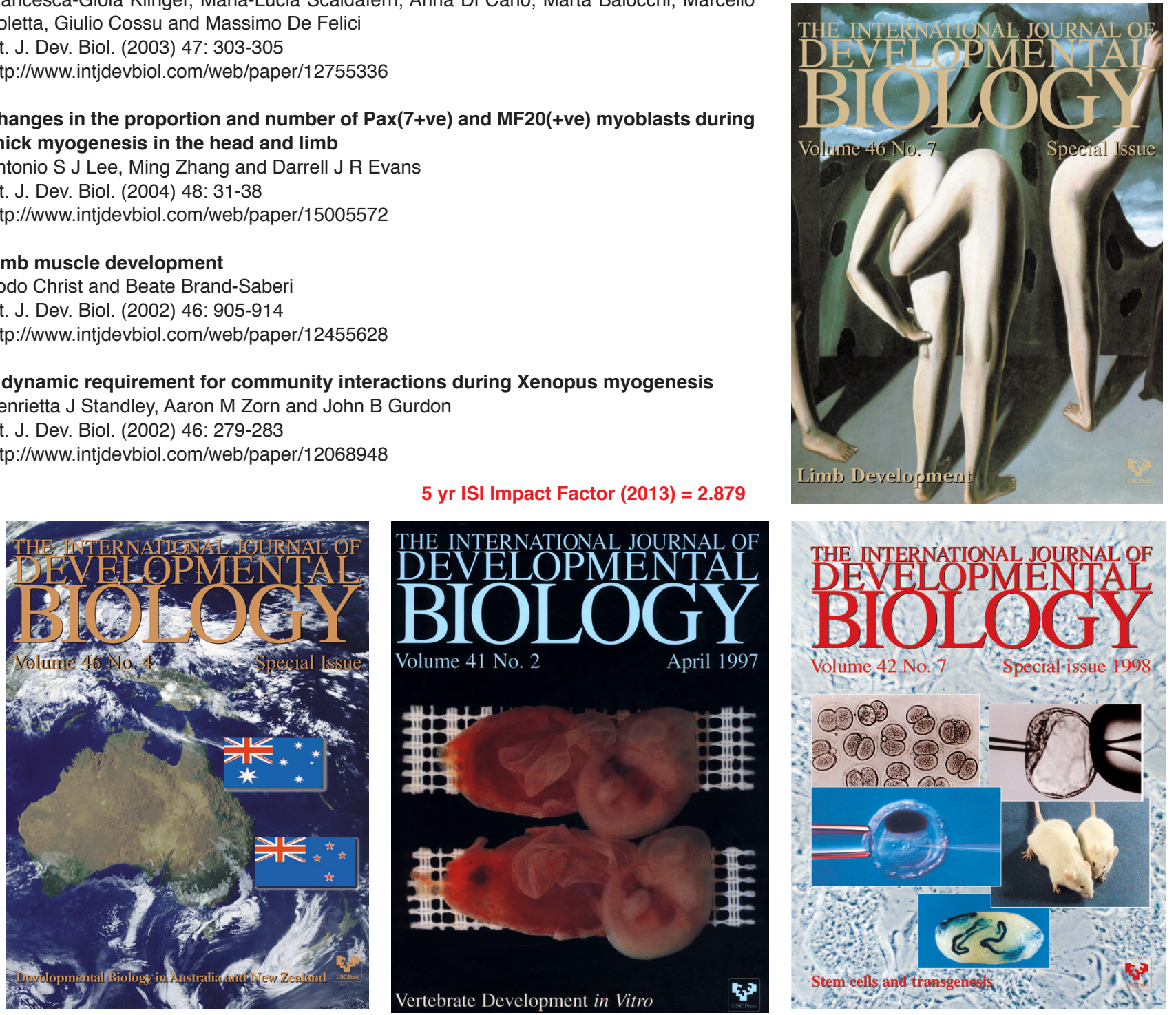